\title{
Use of imaging and clinical data to screen for cardiovascular disease in asymptomatic diabetics
}

Carlos Henrique Reis Esselin Rassi ${ }^{1 \dagger}$, Timothy W. Churchill ${ }^{2 \dagger}$, Carlos A. Fernandes Tavares ${ }^{1}$, Mateus Guimaraes Fahel', Fabricia P. O. Rassi' ${ }^{1}$, Augusto H. Uchida', Bernardo L. Wajchenberg', Antonio C. Lerario ${ }^{1}$, Edward Hulten ${ }^{3}$, Khurram Nasir ${ }^{4}$, Márcio S. Bittencourt ${ }^{3,5}$, Carlos Eduardo Rochitte ${ }^{1^{*}}$ (1) and Ron Blankstein ${ }^{3}$

\begin{abstract}
Background: There is increasing evidence to suggest that not all individuals with type 2 diabetes mellitus (T2DM) have equal risk for developing cardiovascular disease. We sought to compare the yield of testing for pre-clinical atherosclerosis with various approaches.
\end{abstract}

Methods: 98 asymptomatic individuals with T2DM without known coronary artery disease (CAD) were enrolled in a prospective study and underwent carotid ultrasound, exercise treadmill testing (ETT), coronary artery calcium (CAC) scoring, and coronary computed tomography angiography (CTA).

Results: Of 98 subjects (average age $55 \pm 6,64 \%$ female), 43 (44\%) had coronary plaque detectable on CTA, and 38 (39\%) had CAC score $>0$. By CTA, $16(16 \%)$ had coronary stenosis $\geq 50 \%$, including three subjects with CAC $=0$. Subjects with coronary plaque had greater prevalence of carotid plaque ( $58 \%$ vs. $38 \%, p=0.01)$ and greater carotid intima media thickness ( $0.80 \pm 0.20 \mathrm{~mm}$ vs. $0.70 \pm 0.11 \mathrm{~mm}, \mathrm{p}=0.02)$. Notably, 18 of 55 subjects (33\%) with normal CTA had carotid plaque. Eight subjects had a positive ETT, of whom five had $\geq 50 \%$ coronary stenosis, two had $<50 \%$ stenosis, and one had no CAD. Among these tests, CAC scoring had the highest sensitivity and specificity for prediction of CAD.

Conclusion: Among asymptomatic subjects with T2DM, a majority ( $56 \%$ ) had no CAD by CTA. When compared to CTA, CAC was the most accurate screening modality for detection of CAD, while ETT and carotid ultrasound were less sensitive and specific. However, $33 \%$ of subjects with normal coronary CTA had carotid plaque, suggesting that screening for carotid plaque might better characterize stroke risk in such patients.

Keywords: Type 2 diabetes mellitus, Coronary artery disease, Coronary computed tomography angiography

\section{Background}

Cardiovascular disease is the leading cause of morbidity and mortality among individuals with type 2 diabetes

\footnotetext{
*Correspondence: rochitte@incor.usp.br

${ }^{\dagger}$ Carlos Henrique Reis Esselin Rassi and Timothy W. Churchill equally contributed to the development of this manuscript

${ }^{1}$ Heart Institute (InCor), University of São Paulo, Medical School, Brazil, Av. Dr. Enéas de Carvalho Aguiar, 44, Andar AB, Cerqueira César, São Paulo, SP 05403-000, Brazil

Full list of author information is available at the end of the article
}

mellitus (T2DM) [1-3], and diabetics have a higher risk of cardiovascular disease as compared to non-diabetics with a similar risk factor burden [4]. Moreover, once individuals with diabetes present with a coronary heart disease event, they experience a worse prognosis than non-diabetics [5-8]. Unfortunately, diabetics are also known to have a high burden of asymptomatic cardiovascular disease. Thus, a wide variety of clinical strategies have been proposed for identifying diabetics with coronary artery disease (CAD) before it becomes clinically manifest. 
Although screening programs are currently employed in asymptomatic diabetics in some clinical settings, their potential capability to reduce the rate of adverse cardiac outcomes remains unproven $[9,10]$. In part, this may be due to lower than anticipated event rates in clinical trials, as well as widespread use of preventive therapies irrespective of the screening strategy used [11]. While the available studies to date support the use of preventive therapies for most patients with diabetes, the yield and optimal technique for risk stratifying lower-risk individuals with diabetes is uncertain. Despite the lack of proven benefit, there may remain a role for screening selected individuals with diabetes, particularly if the test results could favorably influence downstream medical and lifestyle therapies. In addition, such screening approaches could be useful to provide more individualized assessment when deciding on the intensity of statin therapy, the role of aspirin [12], or potentially in the future, the role of anti-inflammatory therapies [13] and newer lipid lowering agents [14].

Multiple imaging and laboratory techniques are available to detect the presence of pre-clinical disease and consequently characterize an individual's risk of future cardiovascular events. However, it remains uncertain how each of these approaches compare to each other and to more expensive imaging techniques in the risk stratification of individuals with T2DM. Therefore, using coronary computed tomography angiography (CTA) as the reference standard, we sought to compare the use of coronary artery calcium (CAC) scoring, carotid ultrasound, and exercise treadmill testing (ETT) for detecting subclinical CAD among a cohort of asymptomatic patients with diabetes.

\section{Methods}

\section{Patient enrollment}

In this prospective cohort study, 98 asymptomatic subjects with T2DM, as defined by American Diabetes Association criteria [15], were recruited between June 2011 and January 2013 from the Endocrinology Outpatient Clinic of the University of São Paulo School of Medicine Clinics Hospital. The Ethics Committee of the University of São Paulo approved the study, and all patients provided informed consent during their initial visit.

We included individuals aged 40-65 years with a known duration of diabetes of less than 10 years and without known prior cardiovascular disease. Exclusion criteria included a history of heart failure, ischemic heart disease, chest pain, angina, arrhythmia, severe hypertension (blood pressure $>180 / 100 \mathrm{mmHg}$ ), renal or hepatic failure, dyspnea at rest, total cholesterol $>350 \mathrm{mg} / \mathrm{dL}$, low-density lipoprotein (LDL) cholesterol $>250 \mathrm{mg} / \mathrm{dL}$, triglycerides $>500 \mathrm{mg} / \mathrm{dL}$, body mass index (BMI) $>45 \mathrm{~kg} /$ m2, known neoplasm, pregnancy, dementia, and an allergy to iodinated contrast.

Power calculation $[16,17]$ estimates that a sample size of 51 patients would be required for an $\alpha$ of 0.05 and power of 0.8 in order to detect a difference among the sensitivity of the three screening tests, assuming CAC sensitivity to be $90 \%[18,19]$, ETT sensitivity $30 \%$ [20], and carotid ultrasound sensitivity $50 \%[21,22]$ for detection of any coronary plaque. ETT has highly variable previously reported sensitivities for detection of obstructive $\mathrm{CAD}$, but to screen for the presence of any plaque, including non-obstructive, the sensitivity of ETT is lower [20].

\section{Clinical and laboratory evaluation}

All clinical and historical data (e.g. diabetes duration) were prospectively collected by a study physician prior to all imaging and laboratory test results. Laboratory tests included fasting glucose and glycosylated hemoglobin, total cholesterol and cholesterol fractions, triglycerides, creatinine, liver function tests, blood counts, and urine and serum human chorionic gonadotropin $\beta$ (in women of childbearing age). Microalbuminuria was measured using 24-hour urine collection.

\section{Coronary CTA acquisition and analysis}

Coronary CTA and CAC calcium scanning were performed using Toshiba Aquillion One scanner with 320 detectors, $0.5 \mathrm{~mm}$ slice thickness, with gantry rotation of $350 \mathrm{~ms}$. Scan coverage in the $\mathrm{z}$-axis ranged from 12 to $16 \mathrm{~cm}$. For the CTA acquisition, we used tube voltage between $80-135 \mathrm{kV}$ and tube current between 200$580 \mathrm{~mA}$, both selected according to patient BMI. Prior to each scan, the patient's blood pressure and heart rate were assessed, and if the heart rate was above 70 beats per minute, beta-blockers were administered orally. Following oral beta blocker administration, if the heart rate was greater than $64 \mathrm{bpm}$, intravenous metoprolol was administered. We administered $70-100 \mathrm{~mL}$ of iodinated contrast (Iopamiron 370 mg/ml; Bayer Schering Pharma, Berlin, Germany) via an automated injector at a rate of $5 \mathrm{~mL} /$ second. The estimated mean radiation dose for the complete CT protocol (coronary CTA plus CAC scanning) was $7.1 \mathrm{mSv}$ per patient.

All coronary CTA images were transferred to a workstation (Vitrea FX-Vital Image) and analyzed by two experienced cardiac imagers who were blinded to all other data. A standard 18-segment coronary tree model was used [23]. The calcium was calculated according to the Agatston protocol [24].

CAD was defined by the presence of any atherosclerotic plaque, which was defined as a tissue structure $>1 \mathrm{~mm}^{2}$ that was contained within and/or adjacent to the coronary 
artery lumen and could be clearly distinguished from the vessel lumen [25]. Plaques were classified according to the degree of luminal obstruction. Obstructive CAD was defined as the presence of at least one plaque causing a luminal reduction of more than $50 \%$ [23]. In cases of a disagreement between the two examiners, a third experienced cardiologist mediated a consensus.

\section{Other testing modalities}

In addition to CAC scoring and CTA analysis, all subjects underwent exercise treadmill testing and carotid ultrasonography. Exercise treadmill tests were interpreted by an experienced cardiologist who was blinded to all other test results. When considering the exercise protocol, $42 \%$ of subjects exercised using the Bruce protocol, and $52 \%$ with the modified Bruce protocol. Of the remaining six subjects, five underwent test with Ellestad protocol and one with ramp protocol. The ECG was defined as positive if there were horizontal or downsloping ST depressions greater than $1 \mathrm{~mm}$ in two contiguous leads (except aVR) $80 \mathrm{~ms}$ after the J-point. The ETT was considered non-diagnostic if subjects did not achieve $85 \%$ of the age predicted maximum heart rate.

Carotid ultrasounds were interpreted by an experienced radiologist. Carotid intima media thickness (CIMT) was manually measured in both carotid arteries at end diastole over a $1 \mathrm{~cm}$ segment of the common carotid artery located $0.5 \mathrm{~cm}$ below the carotid-artery bulb [26]. CIMT $\geq 1 \mathrm{~mm}$ was defined as abnormal [27]. Carotid plaque was defined as a focal region protruding into the vessel lumen that had either CIMT $\geq 1.5 \mathrm{~mm}$ or focal wall thickening at least $50 \%$ greater than that of the surrounding vessel wall [28].

\section{Statistical analysis}

Continuous variables are presented as mean and standard deviation or as median and quartiles, as appropriate, and tested for significance using two-tailed $t$ test or KruskalWallis test depending on whether the distribution was normal. Categorical variables are presented as absolute values and proportions and tested for significance with a Chi squared test. To compare the diagnostic yield of various screening approached to detect CAD, we calculated sensitivity and specificity for each test, using the presence of any disease by CTA as the reference standard. All statistical analysis was done using Stata 12.1 (StataCorp, College Station, Texas).

\section{Results}

\section{Patient characteristics}

Characteristics of study subjects are shown in Table 1, stratified by the presence of any CAD. Mean age was 54.5 years, and $63(63 \%)$ of subjects were female. The mean hemoglobin A1c was $7.3 \%$ and 22 (22\%) were on insulin therapy. The mean LDL cholesterol was $116.7 \mathrm{mg} /$ dL. Fewer than $50 \%$ of subjects were on statin therapy or aspirin, and 50 (51\%) were on an ACE inhibitor or an ARB. The median 10 -year risk was $13.0 \%$ as assessed by Framingham Risk Score for coronary heart disease, $8.2 \%$ by the 2013 American Heart Association risk calculator, and $11.4 \%$ by United Kingdom Prospective Diabetes Study (UKPDS) risk engine.

\section{Characteristics of patients with coronary artery disease}

Subjects with coronary disease on coronary CTA were more likely to be older and have hypertension, and reported a longer duration of T2DM than subjects without $\mathrm{CAD}$. Among laboratory parameters, only hemoglobin A1c was significantly higher among those with CAD on CTA. Insulin use was more common among those with CAD. Similarly, use of cardiovascular medications, including ACE inhibitors or ARBs and statins, was more common in subjects with CAD. While there was a trend towards increased aspirin use among those with CAD, this did not reach statistical significance $(\mathrm{p}=0.052)$.

\section{Coronary CTA findings}

Results of the coronary CTA are shown in Table 2. Overall, 55 subjects $(56 \%)$ had no CAD, while $27(28 \%)$ had non-obstructive plaque ( $<50 \%$ stenosis). The remaining 16 subjects $(16 \%)$ had at least one coronary stenosis over $50 \%$. Among the 43 subjects with any plaque, 27 (63\%) had disease in multiple coronary vessels, and over one third (16 subjects, or $37 \%$ ) had disease involving greater than four coronary segments. Multivessel obstructive disease (defined as greater than $50 \%$ stenosis in more than one coronary artery) was uncommon; only three subjects had obstructive disease in two arteries and one in all three arteries.

\section{CAC findings}

Overall, 60 subjects $(61 \%)$ did not have any CAC (Table 2). Among the remaining 38 subjects with CAC, the majority (24 subjects, or $63 \%$ ) had Agatston score $<100$, with the remaining 14 (37 \%) having an Agatston score of 100 or greater.

Only five subjects had plaque on coronary CTA despite a CAC of zero. The number of affected coronary segments in these subjects ranged from 1 to 5 , and three of the five individuals had stenosis greater than $50 \%$. Two of these five subjects had carotid plaque, and one had a positive ETT.

Results of carotid ultrasound and exercise treadmill testing Results from carotid ultrasounds and ETT, stratified by the presence of CAD, are presented in Table 3. Mean 
Table 1 Patient characteristics

\begin{tabular}{|c|c|c|c|c|}
\hline & $\begin{array}{l}\text { All subjects } \\
\mathrm{n}=98\end{array}$ & $\begin{array}{l}\text { Coronary artery } \\
\text { disease } n=43(43.9 \%)\end{array}$ & $\begin{array}{l}\text { No coronary artery } \\
\text { disease } n=55(56.1 \%)\end{array}$ & p Value \\
\hline \multicolumn{5}{|l|}{ Demographics } \\
\hline Age, years & $54.5 \pm 6.1$ & $56.5 \pm 5.8$ & $53.0 \pm 5.9$ & $<0.01$ \\
\hline Female sex $(\#, \%)$ & $63(64.3 \%)$ & $24(55.8 \%)$ & $39(70.9 \%)$ & 0.12 \\
\hline \multicolumn{5}{|l|}{ Race $(\#, \%)$} \\
\hline Caucasian & $64(65.3 \%)$ & $33(76.7 \%)$ & $31(56.4 \%)$ & 0.03 \\
\hline Black & 19 (19.4\%) & $4(9.3 \%)$ & $15(27.3 \%)$ & \\
\hline Asian & $7(7.1 \%)$ & $1(2.3 \%)$ & $6(10.9 \%)$ & \\
\hline Other & $8(8.2 \%)$ & $5(11.6 \%)$ & $3(5.5 \%)$ & \\
\hline \multicolumn{5}{|l|}{ Clinical data } \\
\hline Body mass index & $29.4 \pm 4.7$ & $29.5 \pm 4.8$ & $29.3 \pm 4.7$ & 0.83 \\
\hline Abdominal circumference, cm & $103.0 \pm 12.1$ & $105.0 \pm 12.0$ & $101.4 \pm 12.1$ & 0.15 \\
\hline Systolic blood pressure, mmHg & $120.9 \pm 17.2$ & $125.3 \pm 17.3$ & $117.4 \pm 16.5$ & 0.02 \\
\hline Diastolic blood pressure, $\mathrm{mmHg}$ & $71.9 \pm 11.9$ & $73.9 \pm 12.3$ & $70.3 \pm 11.4$ & 0.15 \\
\hline Treatment for hypertension (\#, \%) & $64(65.3)$ & $34(79.1 \%)$ & $30(54.5 \%)$ & 0.01 \\
\hline Duration of diabetes, years & $5.2 \pm 3.3$ & $6.5 \pm 3.2$ & $4.2 \pm 3.0$ & $<0.01$ \\
\hline History of hyperlipidemia (\#, \%) & $55(56.1 \%)$ & $26(60.5 \%)$ & $29(52.7 \%)$ & 0.44 \\
\hline Family history of coronary artery disease (\#,\%) & $10(10.2 \%)$ & $7(16.3 \%)$ & $3(5.5 \%)$ & 0.08 \\
\hline \multicolumn{5}{|l|}{ Smoking status (\#, \%) } \\
\hline Current smoker & $20(20.4 \%)$ & $10(23.3 \%)$ & $10(18.2 \%)$ & 0.74 \\
\hline Former smoker & $8(8.2 \%)$ & $4(9.3 \%)$ & $4(7.3 \%)$ & \\
\hline Never smoker & $70(71.4 \%)$ & $29(67.4 \%)$ & $41(74.5 \%)$ & \\
\hline $\begin{array}{l}\text { Framingham risk score (10-year estimated risk) } \\
\text { (median, interquartile range) }\end{array}$ & $13.0 \%(8.0-16 \%)$ & $13.0 \%(10-20 \%)$ & $13.0 \%(8-16 \%)$ & 0.07 \\
\hline $\begin{array}{l}2013 \text { AHA/ACC risk calculator (10-year risk of } \\
\text { atherosclerotic cardiovascular disease) } \\
\text { (median, interquartile range) }\end{array}$ & $8.2 \%(4.0-16.0 \%)$ & $13.5 \%(5.5-19.7 \%)$ & $7.0 \%(2.3-13 \%)$ & $<0.01$ \\
\hline $\begin{array}{l}\text { UKPDS risk engine 10-year predicted risk of coronary } \\
\text { heart disease (median, interquartile range) }\end{array}$ & $11.4 \%(5.2-19.4 \%)$ & $17.9 \%(11.7-26.2 \%)$ & $7.2 \%(3.8-11.6 \%)$ & $<0.01$ \\
\hline \multicolumn{5}{|l|}{ Laboratory data } \\
\hline Hemoglobin A1c & $7.3 \pm 1.7 \%$ & $8.0 \pm 1.7 \%$ & $6.8 \pm 1.5 \%$ & $<0.01$ \\
\hline Total cholesterol, mg/dL & $193.5 \pm 39.7$ & $198.5 \pm 46.6$ & $189.7 \pm 33.3$ & 0.28 \\
\hline HDL cholesterol, mg/dL & $45.5 \pm 13.2$ & $46.7 \pm 14.3$ & $44.5 \pm 12.5$ & 0.44 \\
\hline LDL cholesterol, mg/dL & $116.7 \pm 35.1$ & $120.6 \pm 41.4$ & $113.7 \pm 29.2$ & 0.33 \\
\hline Triglycerides, mg/dL (median, interquartile range) & $133(103-198)$ & $148(101-213)$ & $129(103-194)$ & 0.46 \\
\hline $\begin{array}{l}\text { Microalbuminuria, mg/24 } \mathrm{h} \text { (median, } \\
\text { interquartile range) }\end{array}$ & $5.8(3.9-11.8)$ & $8.1(3.9-18.7)$ & $5.4(3.7-9.0)$ & 0.09 \\
\hline \multicolumn{5}{|l|}{ Medications } \\
\hline Insulin use (\#,\%) & $22(22.5 \%)$ & $15(34.8 \%)$ & $7(12.7 \%)$ & $<0.01$ \\
\hline Oral hypoglycemic (\#, \%) & $82(83.7 \%)$ & $39(90.7 \%)$ & $43(78.2 \%)$ & 0.10 \\
\hline ACE or ARB (\#,\%) & $50(51.0 \%)$ & $27(62.8 \%)$ & $23(41.8 \%)$ & 0.04 \\
\hline Statin (\#, \%) & $45(45.9 \%)$ & $25(58.1 \%)$ & $20(26.4 \%)$ & 0.03 \\
\hline Aspirin (\#,\%) & $33(33.7 \%)$ & $19(44.2 \%)$ & $14(25.5 \%)$ & 0.052 \\
\hline
\end{tabular}

Values given are mean \pm standard deviation unless otherwise specified

p Values were calculated using two-tailed t test and Chi squared test; Kruskal-Wallis test was used for comparison of medians

CIMT was greater in subjects with CAD. Similarly, a greater proportion of subjects with CAD had carotid plaque than those who did not have any CAD.
Only 8 (8\%) subjects had positive ECG changes during the exercise treadmill test, although $20 \%$ of subjects did not reach maximal predicted heart rate and one 


\begin{tabular}{lc}
$\begin{array}{l}\text { Table } 2 \text { Coronary computed } \\
\text { findings }\end{array}$ & tomography angiography \\
\hline Luminal stenosis on coronary CTA & $55(56.1)$ \\
No stenosis & $13(13.3)$ \\
$1-24 \%$ & $14(14.3)$ \\
$25-49 \%$ & $7(7.1)$ \\
$50-69 \%$ & $9(9.2)$ \\
$70 \%$ or greater & Number of subjects (\%) \\
Number of coronary segments with plaque & $55(56.1)$ \\
0 segments & $27(27.6)$ \\
$1-4$ segments & $16(16.3)$ \\
5 or more segments & Number of subjects (\%) \\
Number of coronary arteries with plaque & $55(56.1)$ \\
No plaque & $16(16.3)$ \\
1 vessel & $15(15.3)$ \\
2 vessels & $12(12.2)$ \\
3 vessels & Number of subjects (\%) \\
Number of coronary arteries with obstructive & \\
disease ( $\geq 50 \%$ stenosis) & $82(83.7)$ \\
No obstructive disease & $12(12.2)$ \\
1 vessel & $3(3.1)$ \\
2 vessels & $1(1.0)$ \\
3 vessels & Number of subjects (\%) \\
Coronary artery calcium (Agatston score) & $60(61.2)$ \\
0 & $24(24.5)$ \\
$1-99$ & $14(14.3)$ \\
100 or greater & \\
\hline & \\
\hline
\end{tabular}

subject had a non-diagnostic test due to baseline leftbundle branch block. Two patients had angina during the exercise treadmill test. Of these, one had ECG changes and considered as a positive test; the other had atypical angina without ECG changes and was considered as a negative test. The number of METS achieved during the test did not differ between the CAD and the non-CAD group (8.2 METs vs. 8.7 METS, $\mathrm{p}=0.19$ ), though subjects with CAD had a lower Duke Treadmill Score than those without $\operatorname{CAD}$ (7.1 vs. 9.2, $\mathrm{p}=0.03$ ).

\section{Predictive value of screening tests and historical parameters for coronary artery disease}

The sensitivity and specificity for each testing modality for the prediction of CAD are shown in Fig. 1. CAC offered the best combination of sensitivity and specificity of any evaluated test to detect CAD. Carotid disease, by contrast, was only modestly predictive of the presence of coronary disease, with sensitivity and specificity in the $60 \%$ range. ETT, in turn, was not sensitive, but had very high specificity. Area under receiver operating characteristics (ROC) curves for these three modalities were 0.94 for CAC, 0.64 for carotid ultrasound, and 0.57 for ETT (Fig. 1); p value was $<0.01$ for comparison of CAC with other modalities, but was non-significant (0.29) for comparison of carotid ultrasound with ETT.

Test characteristics of evaluated historical parameters are shown in Table 4. Of these, hypertension and hyperlipidemia were the most sensitive, while factors relating to severity of diabetes-insulin use, poor glycemic control, and long duration of diabetes-all were relatively insensitive but considerably more specific. Combinations of these parameters yielded decreasing sensitivity and increasing specificity.

The prevalence of CAD, stratified by insulin use and subject age, is presented in Fig. 2. Among non-insulin dependent diabetics, younger subjects had a lower prevalence of CAD. However, among insulin-dependent subjects, there was no significant difference in $C A D$ prevalence by age. The prevalence of CAD also increased by duration of diabetes, as shown in Fig. 3.

\section{Discussion}

In this study of asymptomatic diabetic subjects without known cardiovascular disease, we showed that there is a substantial heterogeneity in the prevalence of subclinical coronary disease, as only $44 \%$ of subjects had evidence of any plaque by coronary CTA and only $16 \%$ had obstructive CAD. When coronary CTA was used as the reference standard, CAC had the highest sensitivity for detection of coronary plaque, while carotid ultrasound, exercise treadmill testing, and risk factors, either alone or in combination, had lower sensitivity and specificity. Finally, we also found that $33 \%$ of the patients who did not have coronary plaque on CTA had atherosclerotic plaque involving the carotid arteries.

\section{Prevalence of subclinical coronary disease}

Perhaps more notable than the $44 \%$ of subjects with coronary disease is the fact that $56 \%$ of the study participants had no atherosclerotic plaque in their coronary arteries. Coronary CTA is a highly sensitive measure for detection of CAD [29,30], and subjects without plaque on CTA correspondingly have a low rate of cardiovascular events and represent a low risk group [31-33]. This finding demonstrates that there is considerable variability in cardiac risk amongst diabetics and brings into question the classification of diabetes as a coronary heart disease equivalent [34]. As a risk stratification tool, screening coronary CTA represents an efficient way to define a subset of diabetics at much lower risk for coronary heart disease, with a number needed to screen of two in order to detect one low risk patient in our population. Nevertheless, further data are needed regarding the role of preventative therapies (or conversely safety of withholding such therapies) in individuals who have T2DM without any atherosclerosis on CTA $[35,36]$. 
Table 3 Results of screening tests stratified by the presence or absence of coronary artery disease

\begin{tabular}{|c|c|c|c|c|}
\hline Screening tests & $\begin{array}{l}\text { All subjects } \\
(\mathrm{n}=98)\end{array}$ & $\begin{array}{l}\text { Subjects with coronary } \\
\text { artery disease }(n=43)\end{array}$ & $\begin{array}{l}\text { Subjects without coronary } \\
\text { artery disease }(n=55)\end{array}$ & p Value \\
\hline \multicolumn{5}{|l|}{ Coronary artery calcium } \\
\hline 0 & $60(61.0 \%)$ & $5(11.6 \%)$ & $55(100 \%)$ & \multirow[t]{2}{*}{$<0.01$} \\
\hline$\geq 1$ (Agatston score) & $38(38.8 \%)$ & $38(88.4 \%)$ & $0(0 \%)$ & \\
\hline \multicolumn{5}{|l|}{ Carotid artery ultrasound } \\
\hline $\begin{array}{l}\text { Maximum intima medial thickness } \\
(\text { IMT), mm }\end{array}$ & $0.75 \pm 0.16$ & $0.80 \pm 0.20$ & $0.70 \pm 0.11$ & $<0.01$ \\
\hline $\mathrm{IMT} \geq 1.0 \mathrm{~mm}(\#, \%)$ & $11(11.2 \%)$ & $11(25.6 \%)$ & 0 & $<0.01$ \\
\hline \multicolumn{5}{|l|}{ Carotid plaque (\#,\%) } \\
\hline No carotid plaque & $55(56.1 \%)$ & 18 (41.9\%) & $37(67.3 \%)$ & \multirow[t]{2}{*}{0.01} \\
\hline Carotid plaque & $43(43.9 \%)$ & $25(58.4 \%)$ & $18(32.7 \%)$ & \\
\hline Carotid plaque or IMT $\geq 1.0 \mathrm{~mm}$ & $44(44.9 \%)$ & $26(60.5 \%)$ & $18(32.7 \%)$ & $<0.01$ \\
\hline \multicolumn{5}{|l|}{ Exercise treadmill test } \\
\hline \multicolumn{5}{|l|}{ ECG test results (\#, \%) } \\
\hline Negative & $69(70.4 \%)$ & $26(60.5 \%)$ & $43(78.2 \%)$ & \multirow[t]{4}{*}{0.04} \\
\hline Positive & $8(8.2 \%)$ & $7(16.3 \%)$ & $1(1.8 \%)$ & \\
\hline Negative with $<85 \%$ MPHR & $20(20.4 \%)$ & $10(23.3 \%)$ & $10(18.2 \%)$ & \\
\hline Inconclusive due to LBBB & $1(1.0 \%)$ & 0 & $1(1.8 \%)$ & \\
\hline \multicolumn{5}{|l|}{ Specific test outcomes } \\
\hline METS & $8.5 \pm 2.1$ & $8.2 \pm 1.8$ & $8.7 \pm 2.4$ & 0.19 \\
\hline Duke treadmill score & $8.3 \pm 4.8$ & $7.1 \pm 5.0$ & $9.2 \pm 4.4$ & 0.03 \\
\hline
\end{tabular}

$\mathrm{p}$ Values calculated using two-tailed $\mathrm{t}$ test, Chi squared test, and Kruskal-Wallis test MPHR maximal predicted heart rate

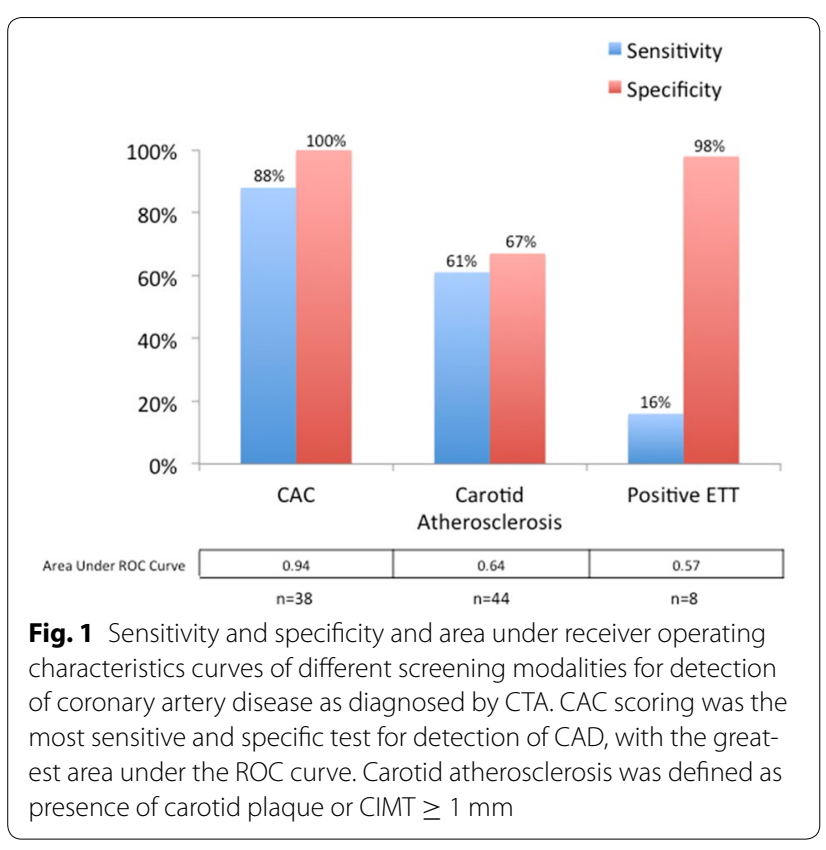

The proportion of subjects with normal coronary arteries was greater in our population than in most published series, which have reported prevalence rates of normal CTA in individuals with diabetes ranging from 13-34 \% of subjects [31, 37-40]. Most published data, however, pertain to subjects referred for coronary CTA, who had either symptoms concerning for obstructive CAD or an abnormal prior stress test. However, even when we compared the prevalence of normal CTA in our study to other screening populations of asymptomatic diabetics, we observed a higher rate in our population. For example, in the FACTOR 64 trial, a large, multi-center study of coronary CTA in asymptomatic diabetics, $31 \%$ of subjects had a normal CTA. This difference likely reflects the fact that FACTOR 64 enrolled a population of diabetics with higher cardiovascular risk-when compared to our study, the FACTOR 64 population had a greater proportion of men, an older cohort (62 vs. 55 years in our study), a longer duration of diabetes (13.9 vs. 5.2 years), and a higher rate of insulin use (43 vs. $22 \%$ ) [41].

\section{Screening modalities for coronary disease}

Among the screening modalities tested in our study, we found that $\mathrm{CAC}$ scoring had the greatest sensitivity and specificity for detection of CAD. The strong test characteristics of calcium scoring are unsurprising, as CAC is by definition $100 \%$ specific for coronary plaque and the sensitivity is only limited by the presence of exclusively non-calcified plaque.

In our sample, the subset whose CAD would be missed by calcium scoring-those with coronary plaque but 
Table 4 Test characteristics of clinical data for prediction of coronary artery disease detected by coronary CTA

\begin{tabular}{|c|c|c|c|c|}
\hline & Definition of positive & $\begin{array}{l}\text { Frequency } \\
\text { (total } n=98)(\%)\end{array}$ & $\begin{array}{l}\text { Sensitivity } \\
\text { (\%) }\end{array}$ & $\begin{array}{l}\text { Specificity } \\
(\%)\end{array}$ \\
\hline \multicolumn{5}{|l|}{ Clinical variables } \\
\hline Age $\geq 50$ years & Age $\geq 50$ years & $75(77)$ & 83.7 & 29.1 \\
\hline Age $\geq 55$ years & Age $\geq 55$ years & $44(44.9)$ & 60.5 & 67.3 \\
\hline \multicolumn{5}{|l|}{ High risk clinical criteria } \\
\hline Hypertension & $\begin{array}{l}\text { History of hypertension, current treatment, or } \\
\text { SBP } \geq 140 \mathrm{mmHg}\end{array}$ & $65(66.3)$ & 81.4 & 45.5 \\
\hline Hyperlipidemia & LDL cholesterol $\geq 130 \mathrm{mg} / \mathrm{dL}$ or statin therapy & $65(66.3)$ & 76.7 & 41.8 \\
\hline Insulin use & Current insulin use at time of CTA & $22(22.5)$ & 34.9 & 87.3 \\
\hline Poor glycemic control & Hemoglobin A1c $\geq 8.0 \%$ & $30(30.6)$ & 46.5 & 81.8 \\
\hline Long duration of diabetes & Duration of DM > 6 years & $33(33.7)$ & 51.2 & 80.0 \\
\hline \multicolumn{5}{|c|}{ Combinations of high risk clinical criteria } \\
\hline At least 1 high risk clinical criterion & $\geq 1$ criterion defined above & $87(88.8)$ & 95.3 & 16.4 \\
\hline At least 2 high risk clinical criteria & $\geq 2$ criteria defined above & $65(66.3)$ & 86.0 & 49.1 \\
\hline At least 3 high risk clinical criteria & $\geq 3$ criteria defined above & $38(38.8)$ & 65.1 & 81.8 \\
\hline At least 4 high risk clinical criteria & $\geq 4$ criteria defined above & $15(15.3)$ & 27.9 & 94.5 \\
\hline At least 5 high risk clinical criteria & 5 criteria defined above & $8(8.2)$ & 16.3 & 98.2 \\
\hline
\end{tabular}

Coronary artery disease defined as the presence of any coronary artery plaque on CTA

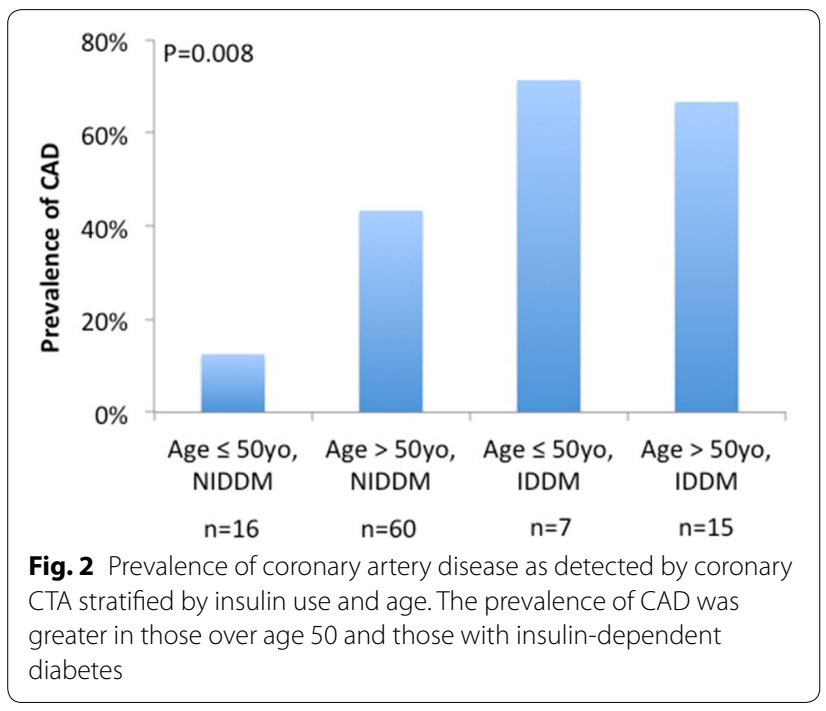

without coronary calcium-represented $5 \%$ of the total population and $8 \%$ of those with a calcium score of zero. Other authors have found higher rates of coronary plaque in such patients without any coronary calcium [42]. However, since most prior studies have demonstrated an extremely low event rate for patients with CAC scores of zero, it is unclear whether the presence of exclusively non-calcified plaque is associated with any meaningful increase in cardiovascular risk [43].

By contrast, exercise treadmill testing was insensitive, but quite specific for the presence of coronary disease, a conclusion that is in keeping with prior studies of ETT

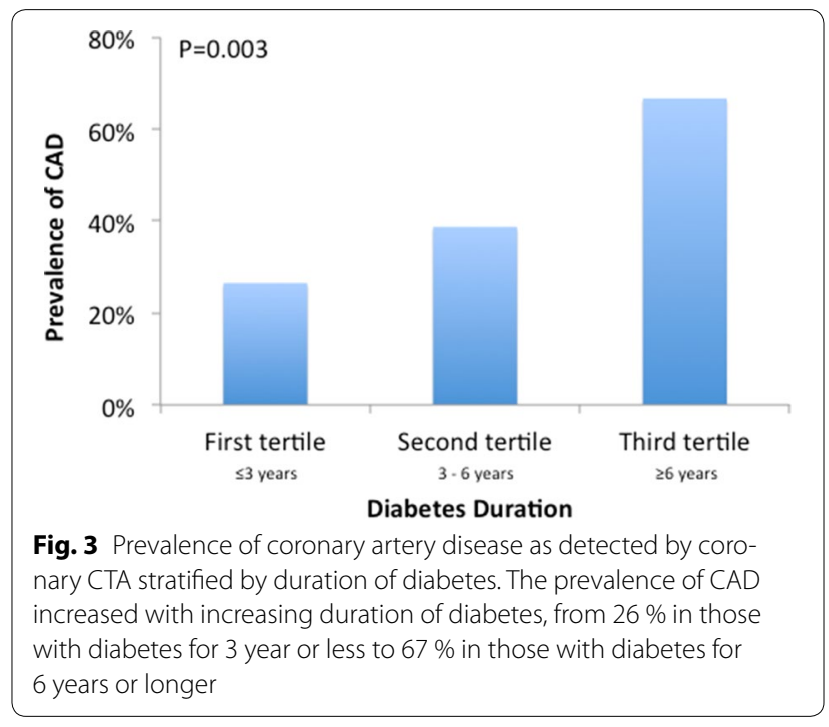

in diabetic populations [44-47]. This result is consistent with our pathophysiologic understanding of exercise testing, as a positive ETT requires the presence of flow-limiting coronary disease, which implies a more advanced coronary lesion. The proportion of subjects with nondiagnostic testing is also in-line with prior series $[44,48]$.

Carotid ultrasound had only modest results in both sensitivity and specificity, suggesting that this is a less useful test for the evaluation of possible coronary heart disease in this population. Similar to our findings, Djaberi et al. [49] evaluated 150 asymptomatic diabetics, using a lower CIMT cutoff of $0.62 \mathrm{~mm}$, and reported a 
sensitivity and specificity of 76 and $71 \%$, respectively for prediction of any coronary atherosclerosis. Other data, mostly in non-diabetic cohorts, have varied on this subject. Guarici and colleagues [50], in a moderate risk group of symptomatic patients, were able to demonstrate CIMT to be independently predictive of obstructive coronary plaque. Other series, by contrast, have not found any association between carotid IMT and the presence of coronary atherosclerosis by CTA [51]. While there are data supporting the association between carotid disease (both increased CIMT and carotid plaque) and coronary heart disease events [52-55], the presence of carotid disease likely has a stronger association with stroke; data from MESA support this, demonstrating that CAC was a much stronger predictor of coronary events than carotid ultrasound measures [56].

\section{Carotid disease in the absence of CAD}

Interestingly, almost one-third of subjects in our study who did not have CAD were found to have carotid artery plaque on carotid ultrasound. This represents a potentially intriguing subgroup, as these subjects are low riskby virtue of their absence of CAD-from a coronary perspective but may have elevated cerebrovascular risk [57], especially since diabetes itself is also a risk factor for cerebrovascular disease [58]. A similar population of patients-with carotid atherosclerosis but without coronary disease-was described in a recent paper by Cohen et al. [59] who demonstrated that, in a cohort of 150 predominantly non-diabetic patients referred for coronary CTA, 52 \% (33 of 63) of those without any CAD on coronary CTA had carotid plaque.

The exact clinical implications of this finding, however, remain unclear, and data are mixed as to whether carotid plaque represents a significant cerebrovascular risk factor in diabetics above and beyond traditional cardiovascular risk factors, as associations between carotid plaque and stroke often do not retain statistical significance in multivariate models or do so only in certain subsets of patients [27, 60, 61]. Carotid atherosclerosis may also herald atherosclerosis in other vascular beds, and this population may be at increased risk of developing incident cardiovascular disease other than stroke. Thus, future studies are warranted regarding the prognostic implications of having carotid plaque in the absence of coronary atherosclerosis.

\section{Other markers of risk}

Our data also show higher prevalence of CAD in subjects on insulin therapy and an association between the presence of CAD and both insulin use and duration of diabetes. Subjects receiving insulin and those who had carried a diagnosis of diabetes for a longer period of time had greater prevalence of CAD, and insulin use was the most specific single clinical characteristic for the presence of coronary disease. Insulin use has previously been associated with a greater extent of coronary disease in diabetics [31, 62], and duration of diabetes has also been associated with worse clinical outcomes [63]. However, these two characteristics are rarely highlighted as part of a practical, clinical approach to risk stratification, despite the presence of a potential pathophysiological link and potential clinical utility of those findings [62].

\section{Screening in asymptomatic diabetics}

Despite the inherent appeal of early detection of CAD, studies of screening for coronary disease in asymptomatic diabetics have thus far not shown a convincing benefit. The Detection of Ischemia in Asymptomatic Diabetics (DIAD) study, the first large-scale, randomized trial to assess a screening program in asymptomatic diabetics, did not find a difference in adverse cardiac outcomes between screened and unscreened subjects [9]. Importantly, though, this study screened subjects with SPECT myocardial perfusion imaging, a test less sensitive than coronary CTA for detection of CAD, and rates of modern medical therapy (statins, aspirin, beta blockers, ACE inhibitors) were high and similar in both groups.

The more recent FACTOR-64 trial addressed this limitation, using coronary CTA to screen asymptomatic diabetics, but similarly did not demonstrate a beneficial effect of screening on hard cardiovascular outcomes [41]. In this case, just as with DIAD, one of the most salient features of the trial was again the low event rate-less than $2 \%$ annually-which was substantially less than the $16 \%$ event rate over 2 years that had been anticipated for the study's power calculation. This difference reflected the excellent background medical therapy, with $\sim 75 \%$ of study participants having an LDL cholesterol $<100 \mathrm{mg} /$ $\mathrm{dL}$ at baseline.

According to the 2013 American College of Cardiology/American Heart Association cholesterol guidelines, all diabetics - and therefore all subjects in our studyshould be treated with a moderate or high-intensity statin [64]. However, statin therapy is not without adverse effects [65-68], and it is conceivable that subjects without coronary disease may not experience sufficient benefit of statin therapy, although further research is required in this area. Specifically, what the DIAD and FACTOR-64 studies did not address was whether subjects with negative screening tests might safely avoid some preventative therapies. Within our cohort, screening with coronary CTA identified over $50 \%$ of subjects as having low risk for coronary heart disease, suggesting that a significant proportion of individuals who might choose, based on their preferences, to focus on lifestyle therapies while deferring 
pharmacological treatments. Nevertheless, further studies are needed regarding the role of statin therapy to reduce the lifetime risk of future cardiovascular events in individuals who do not have evidence of coronary plaque.

\section{Limitations}

Our study is limited by its small size, composed of 98 individuals. However, we examined a homogenous and well-defined cohort, consisting only of asymptomatic subjects with diabetes who had no known cardiovascular or renal disease. In addition, despite its small size, our study is unique as it is the only study of which we are aware that has correlated the findings of CAC scoring, carotid ultrasonography, ETT and biochemical testing against the gold standard of coronary CTA in asymptomatic individuals with diabetes. We did not incorporate data on visceral adiposity or the relative severity of body fat, both of which have been shown to be associated with subclinical atherosclerosis [69, 70]. Finally, another limitation is that our data are cross-sectional and lack information on clinical outcomes. However, it is well documented that CAC scoring and the presence of CAD by CTA are strong predictors of cardiovascular events among subjects with diabetes [31,71-76].

\section{Conclusion}

Within this population of asymptomatic subjects with diabetes, $56 \%$ did not have any atherosclerotic coronary artery disease by coronary CTA, a finding that highlights the heterogeneity of cardiovascular risk in diabetics. Further research is required to better delineate whether there is any clinical role for screening programs to detect such individuals. Such screening could be used to individualize the intensity of lifestyle and pharmacotherapy based on risk level as well as patient preferences. When compared to coronary CTA, screening for CAC was the most accurate method for detection of subclinical coronary artery disease, as compared to carotid ultrasonography or exercise treadmill testing. Finally, a substantial proportion of subjects without CAD had detectable carotid artery plaque, and further investigation is needed to understand both if this represents a population at increased risk of adverse events and whether any interventions might decrease this risk.

\footnotetext{
Abbreviations

BMI: body mass index; CAC: coronary artery calcium; CAD: coronary artery disease; CIMT: carotid intima media thickness; CTA: computed tomography angiography; ECG: electrocardiogram; ETT: exercise treadmill testing; T2DM: type 2 diabetes mellitus.
}

\section{Authors' contributions}

CHRES conceived the project, led study recruitment and data acquisition, was the primary reader on coronary CTAs and helped structure the analysis. TWC developed the analytic approach, performed the statistical analysis and was the primary writer drafting the manuscript. CAFT, FPOR, ACL and BLW participated in subject recruitment and manuscript revision. AHU participated in interpretation of imaging studies and manuscript revision. EH, KN and MSB participated in data analysis and critical revision of manuscript. CER participated in conception and design of project, data analysis, critical revision of manuscript and study supervision. RB participated in analytic design, data analysis, critical revision of manuscript and study supervision. All authors read and approved the final manuscript.

\section{Author details}

${ }^{1}$ Heart Institute (InCor), University of São Paulo, Medical School, Brazil, Av. Dr. Enéas de Carvalho Aguiar, 44, Andar AB, Cerqueira César, São Paulo, SP 05403-000, Brazil. ${ }^{2}$ Department of Medicine, Brigham and Women's Hospital, 75 Francis St, Boston, MA 02115, USA. ${ }^{3}$ Division of Cardiovascular Medicine, Brigham and Women's Hospital, 75 Francis St, Boston, MA 02115 , USA. ${ }^{4}$ Department of Cardiology, Baptist Health South Florida, $8900 \mathrm{~N}$. Kendall Drive, Miami, FL 33176, USA. ${ }^{5}$ Center for Clinical and Epidemiological Research, Division of Internal Medicine, University Hospital, and State of São Paulo Cancer Institute (ICESP), University of São Paulo, São Paulo, Brazil.

\section{Competing interests}

The authors declare that they have no competing interests.

This work is part of PhD thesis of Dr. Carlos Henrique Reis Esselin Rassi that will be presented to the Heart Institute (InCor), University of São Paulo, Medical School, Brazil.

Received: 16 September 2015 Accepted: 13 January 2016 Published online: 09 February 2016

\section{References}

1. Nesto RW, Rutter MK. Impact of the atherosclerotic process in patients with diabetes. Acta Diabetol. 2002;39(Suppl 2):S22-8.

2. Redberg RF, Greenland P, Fuster V, Pyorala K, Blair SN, Folsom AR, et al. Prevention Conference VI: Diabetes and Cardiovascular Disease: Writing Group III: risk assessment in persons with diabetes. Circulation. 2002;105(18):e144-52.

3. Morrish NJ, Wang SL, Stevens LK, Fuller JH, Keen H. Mortality and causes of death in the WHO multinational study of vascular disease in diabetes. Diabetologia. 2001;44(Suppl 2):S14-21.

4. Sarwar N, Gao P, Seshasai SR, Gobin R, Kaptoge S, Di Angelantonio E, et al. Diabetes mellitus, fasting blood glucose concentration, and risk of vascular disease: a collaborative meta-analysis of 102 prospective studies. Lancet. 2010;375(9733):2215-22.

5. Malmberg K, Yusuf S, Gerstein HC, Brown J, Zhao F, Hunt D, et al. Impact of diabetes on long-term prognosis in patients with unstable angina and nonQ-wave myocardial infarction: results of the OASIS (Organization to Assess Strategies for Ischemic Syndromes) Registry. Circulation. 2000;102(9):1014-9.

6. Donnan PT, Donnelly L, New JP, Morris AD. Derivation and validation of a prediction score for major coronary heart disease events in a UK type 2 diabetic population. Diabetes Care. 2006;29(6):1231-6.

7. Fava S, Azzopardi J, Muscat HA, Fenech FF. Factors that influence outcome in diabetic subjects with myocardial infarction. Diabetes Care. 1993;16(12):1615-8.

8. Herlitz J, Malmberg K, Karlson BW, Ryden L, Hjalmarson A. Mortality and morbidity during a five-year follow-up of diabetics with myocardial infarction. Acta medica Scandinavica. 1988;224(1):31-8.

9. Young LH, Wackers FJ, Chyun DA, Davey JA, Barrett EJ, Taillefer R, et al. Cardiac outcomes after screening for asymptomatic coronary artery disease in patients with type 2 diabetes: the DIAD study: a randomized controlled trial. JAMA. 2009;301(15):1547-55.

10. Muhlestein JB, Lappe DL, Lima JA, Rosen BD, May HT, Knight S, et al. Effect of screening for coronary artery disease using CT angiography on mortality and cardiac events in high-risk patients with diabetes: the FACTOR-64 randomized clinical trial. JAMA. 2014;312(21):2234-43.

11. Gibbons RJ. Optimal medical therapy vs CT angiography screening for patients with diabetes. JAMA. 2014;312(21):2219-20. 
12. Miedema MD, Duprez DA, Misialek JR, Blaha MJ, Nasir K, Silverman MG, et al. Use of coronary artery calcium testing to guide aspirin utilization for primary prevention: estimates from the multi-ethnic study of atherosclerosis. Circu Cardiovasc Qual Outcomes. 2014;7(3):453-60.

13. Ridker PM. Testing the inflammatory hypothesis of atherothrombosis: scientific rationale for the cardiovascular inflammation reduction trial (CIRT). J Thromb Haemost. 2009;7:332-9.

14. Stein EA, Mellis S, Yancopoulos GD, Stahl N, Logan D, Smith WB, et al. Effect of a monoclonal antibody to PCSK9 on LDL cholesterol. NEngl J Med. 2012;366(12):1108-18.

15. American Diabetes A. Diagnosis and classification of diabetes mellitus. Diabetes care. 2010;33((Suppl 1)):S62-9.

16. Casagrande JT, Pike MC. An improved approximate formula for calculating sample sizes for comparing two binomial distributions. Biometrics. 1978;34(3):483-6.

17. Computer program to calculate sample size requirement to evaluate sensitivity and specificity of a predictive test. https://www.statstodo.com/ SSizSenSpc_Pgm.php. Accessed 17 Dec 2015.

18. Kral BG, Becker LC, Vaidya D, Yanek LR, Qayyum R, Zimmerman SL, et al. Noncalcified coronary plaque volumes in healthy people with a family history of early onset coronary artery disease. Circ Cardiovasc Imaging 2014;7(3):446-53.

19. Hausleiter J, Meyer T, Hadamitzky M, Kastrati A, Martinoff S, Schomig A. Prevalence of noncalcified coronary plaques by 64-slice computed tomography in patients with an intermediate risk for significant coronary artery disease. J Am Coll Cardiol. 2006;48(2):312-8.

20. Blankstein R, Ahmed W, Bamberg F, Rogers IS, Schlett CL, Nasir K, et al. Comparison of exercise treadmill testing with cardiac computed tomography angiography among patients presenting to the emergency room with chest pain: the Rule Out Myocardial Infarction Using ComputerAssisted Tomography (ROMICAT) study. Circ Cardiovasc Imaging. 2012;5(2):233-42.

21. Kablak-Ziembicka A, Tracz W, Przewlocki T, Pieniazek P, Sokolowski A, Konieczynska M. Association of increased carotid intima-media thickness with the extent of coronary artery disease. Heart. 2004;90(11):1286-90

22. Timoteo AT, Carmo MM, Ferreira RC. Carotid intima-media thickness and carotid plaques improves prediction of obstructive angiographic coronary artery disease in women. Angiology. 2013;64(1):57-63.

23. Raff GL, Abidov A, Achenbach S, Berman DS, Boxt LM, Budoff MJ, et al. SCCT guidelines for the interpretation and reporting of coronary computed tomographic angiography. J Cardiovasc Comput Tomogr. 2009;3(2):122-36.

24. Agatston AS, Janowitz WR, Hildner FJ, Zusmer NR, Viamonte M Jr, Detrano R. Quantification of coronary artery calcium using ultrafast computed tomography. J Am Coll Cardiol. 1990;15(4):827-32.

25. Leber AW, Knez A, Becker A, Becker C, von Ziegler F, Nikolaou K, et al. Accuracy of multidetector spiral computed tomography in identifying and differentiating the composition of coronary atherosclerotic plaques: a comparative study with intracoronary ultrasound. J Am Coll Cardiol. 2004;43(7):1241-7.

26. Polak JF, Pencina MJ, Meisner A, Pencina KM, Brown LS, Wolf PA, et al. Associations of carotid artery intima-media thickness (IMT) with risk factors and prevalent cardiovascular disease: comparison of mean common carotid artery IMT with maximum internal carotid artery IMT. J Ultrasound Med. 2010;29(12):1759-68.

27. Prati P, Tosetto A, Vanuzzo D, Bader G, Casaroli M, Canciani L, et al. Carotid intima media thickness and plaques can predict the occurrence of ischemic cerebrovascular events. Stroke. 2008;39(9):2470-6.

28. Polak JF, O'Leary DH, Kronmal RA, Wolfson SK, Bond MG, Tracy RP, et al. Sonographic evaluation of carotid artery atherosclerosis in the elderly: relationship of disease severity to stroke and transient ischemic attack. Radiology. 1993;188(2):363-70.

29. Meijboom WB, Meijs MF, Schuijf JD, Cramer MJ, Mollet NR, van Mieghem CA, et al. Diagnostic accuracy of 64-slice computed tomography coronary angiography: a prospective, multicenter, multivendor study. J Am Coll Cardiol. 2008;52(25):2135-44.

30. Schuijf JD, Bax JJ, Jukema JW, Lamb HJ, Vliegen HW, van der Wall EE, et al. Noninvasive evaluation of the coronary arteries with multislice computed tomography in hypertensive patients. Hypertension. 2005;45(2):227-32.
31. Hulten E, Bittencourt MS, O'Leary D, Shah R, Ghoshhajra B, Christman MP, Montana P, Steigner M, Truong QA, Nasir K, et al. Cardiometabolic risk is associated with atherosclerotic burden and prognosis: results from the partners coronary computed tomography angiography registry. Diabetes Care. 2013;37:555.

32. Van Werkhoven JM, Cademartiri F, Seitun S, Maffei E, Palumbo A, Martini $C$, et al. Diabetes: prognostic value of CT coronary angiography-comparison with a nondiabetic population. Radiology. 2010;256(1):83-92.

33. Bittencourt MS, Hulten E, Ghoshhajra B, O'Leary D, Christman MP, Montana $\mathrm{P}$, et al. Prognostic value of nonobstructive and obstructive coronary artery disease detected by coronary computed tomography angiography to identify cardiovascular events. Circ Cardiovasc Imaging. 2014;7(2):282-91.

34. Haffner SM, Lehto S, Ronnemaa T, Pyorala K, Laakso M. Mortality from coronary heart disease in subjects with type 2 diabetes and in nondiabetic subjects with and without prior myocardial infarction. N Engl J Med. 1998;339(4):229-34.

35. Silverman MG, Blaha MJ, Budoff MJ, Rivera JJ, Raggi P, Shaw LJ, et al. Potential implications of coronary artery calcium testing for guiding aspirin use among asymptomatic individuals with diabetes. Diabetes Care. 2012;35(3):624-6.

36. Bittencourt MS, Blaha MJ, Blankstein R, Budoff M, Vargas JD, Blumenthal RS, et al. Polypill therapy, subclinical atherosclerosis, and cardiovascular events-implications for the use of preventive pharmacotherapy: mESA (Multi-Ethnic Study of Atherosclerosis). J Am Coll Cardiol. 2014;63(5):434-43.

37. Choi EK, Chun EJ, Choi SI, Chang SA, Choi SH, Lim S, et al. Assessment of subclinical coronary atherosclerosis in asymptomatic patients with type 2 diabetes mellitus with single photon emission computed tomography and coronary computed tomography angiography. Am J Cardiol. 2009;104(7):890-6.

38. Hadamitzky M, Hein F, Meyer T, Bischoff B, Martinoff S, Schomig A, et al. Prognostic value of coronary computed tomographic angiography in diabetic patients without known coronary artery disease. Diabetes Care. 2010;33(6):1358-63.

39. Rana JS, Dunning A, Achenbach S, Al-Mallah M, Budoff MJ, Cademartiri $F$, et al. Differences in prevalence, extent, severity, and prognosis of coronary artery disease among patients with and without diabetes undergoing coronary computed tomography angiography: results from 10,110 individuals from the CONFIRM (COronary CT Angiography EvaluatioN For Clinical Outcomes): an InteRnational Multicenter Registry. Diabetes Care. 2012;35(8):1787-94.

40. Leem J, Hee Koh E, Jeong E, Jang JE, Lee SW, Kang JW, Lim TH, Lee WJ, Kim MS, Park JY, et al. Prevalence of angiographically defined obstructive coronary artery disease in asymptomatic patients with type 2 diabetes according to the coronary calcium score. Intern Med. 2012;51(21):3017-23.

41. Muhlestein JB, Lappe DL, Lima JA, Rosen BD, May HT, Knight S, Bluemke DA, Towner SR, Le V, Bair TL, et al. Effect of screening for coronary artery disease using CT angiography on mortality and cardiac events in highrisk patients with diabetes: the Factor-64 randomized clinical trial. JAMA. 2014;312:2234.

42. Schroeder B, Francis G, Leipsic J, Heilbron B, John Mancini GB, Taylor CM. Early atherosclerosis detection in asymptomatic patients: a comparison of carotid ultrasound, coronary artery calcium score, and coronary computed tomography angiography. Can J Cardiol. 2013;29(12):1687-94.

43. Hulten E, Bittencourt MS, Ghoshhajra B, O'Leary D, Christman MP, Blaha $\mathrm{MJ}$, et al. Incremental prognostic value of coronary artery calcium score versus CT angiography among symptomatic patients without known coronary artery disease. Atherosclerosis. 2014;233(1):190-5.

44. Bacci S, Villella M, Villella A, Langialonga T, Grilli M, Rauseo A, et al. Screening for silent myocardial ischaemia in type 2 diabetic patients with additional atherogenic risk factors: applicability and accuracy of the exercise stress test. Eur J Endocrinol. 2002;147(5):649-54.

45. Kim MK, Baek KH, Song KH, Kwon HS, Lee JM, Kang MI, et al. Exercise treadmill test in detecting asymptomatic coronary artery disease in type 2 diabetes mellitus. Diabetes Metab J. 2011;35(1):34-40.

46. Koistinen MJ, Huikuri HV, Pirttiaho H, Linnaluoto MK, Takkunen JT. Evaluation of exercise electrocardiography and thallium tomographic imaging 
in detecting asymptomatic coronary artery disease in diabetic patients. Br Heart J. 1990;63(1):7-11.

47. Gheydari ME, Jamali M, Hajsheikholeslami F, Yazdani S, Jamali M. Value of exercise tolerance testing in evaluation of diabetic patients presented with atypical chest discomfort. Int J Endocrinol Metab. 2013;11(1):11-5.

48. Christman MP, Bittencourt MS, Hulten E, Saksena E, Hainer J, Skali H, et al. Yield of downstream tests after exercise treadmill testing: a prospective cohort study. J Am Coll Cardiol. 2014;63(13):1264-74.

49. Djaberi R, Schuijf JD, de Koning EJ, Rabelink TJ, Smit JW, Kroft LJ, et al. Usefulness of carotid intima-media thickness in patients with diabetes mellitus as a predictor of coronary artery disease. Am J Cardiol. 2009;104(8):1041-6.

50. Guaricci Al, Arcadi T, Brunetti ND, Maffei E, Montrone D, Martini C, et al. Carotid intima media thickness and coronary atherosclerosis linkage in symptomatic intermediate risk patients evaluated by coronary computed tomography angiography. Int J Cardiol. 2014;176(3):988-93.

51. Brolin EB, Agewall S, Brismar TB, Caidahl K, Tornvall P, Cederlund K. Neither endothelial function nor carotid artery intima-media thickness predicts coronary computed tomography angiography plaque burden in clinically healthy subjects: a cross-sectional study. BMC Cardiovasc Disord. 2015;15:63.

52. Den Ruijter HM, Peters SA, Anderson TJ, Britton AR, Dekker JM, Eijkemans $\mathrm{MJ}$, et al. Common carotid intima-media thickness measurements in cardiovascular risk prediction: a meta-analysis. JAMA. 2012;308(8):796-803.

53. O'Leary DH, Polak JF, Kronmal RA, Manolio TA, Burke GL, Wolfson SK Jr. Carotid-artery intima and media thickness as a risk factor for myocardial infarction and stroke in older adults. Cardiovascular Health Study Collaborative Research Group. N Engl J Med. 1999;340(1):14-22.

54. van den Oord SC, Sijbrands EJ, ten Kate GL, van Klaveren D, van Domburg RT, van der Steen AF, et al. Carotid intima-media thickness for cardiovascular risk assessment: systematic review and meta-analysis. Atherosclerosis. 2013;228(1):1-11.

55. Stein JH, Korcarz CE, Hurst RT, Lonn E, Kendall CB, Mohler ER, Najjar SS, Rembold CM, Post WS. Use of carotid ultrasound to identify subclinical vascular disease and evaluate cardiovascular disease risk: a consensus statement from the american society of echocardiography carotid intima-media thickness task force. Endorsed by the society for vascular medicine. J Am Soc Echocardiogr. 2008;21(2):93-111 (quiz 189-190).

56. Gepner AD, Young R, Delaney JA, Tattersall MC, Blaha MJ, Post WS, Gottesman RF, Kronmal R, Budoff MJ, Burke GL, et al. Comparison of coronary artery calcium presence, carotid plaque presence, and carotid intimamedia thickness for cardiovascular disease prediction in the Multi-Ethnic Study of Atherosclerosis. Circ Cardiovasc Imaging; 2015, 8(1).

57. Mathiesen EB, Johnsen SH, Wilsgaard T, Bonaa KH, Lochen ML, Njolstad I. Carotid plaque area and intima-media thickness in prediction of firstever ischemic stroke: a 10-year follow-up of 6584 men and women: the Tromso Study. Stroke. 2011;42(4):972-8.

58. Kissela BM, Khoury J, Kleindorfer D, Woo D, Schneider A, Alwell K, et al. Epidemiology of ischemic stroke in patients with diabetes: the greater Cincinnati/Northern Kentucky Stroke Study. Diabetes Care. 2005;28(2):355-9.

59. Cohen Gl, Aboufakher R, Bess R, Frank J, Othman M, Doan D, et al. Relationship between carotid disease on ultrasound and coronary disease on CT angiography. JACC Cardiovasc Imaging. 2013;6(11):1160-7.

60. Lee EJ, Kim HJ, Bae JM, Kim JC, Han HJ, Park CS, et al. Relevance of common carotid intima-media thickness and carotid plaque as risk factors for ischemic stroke in patients with type 2 diabetes mellitus. AJNR Am J Neuroradiol. 2007;28(5):916-9.
61. Rundek T, Arif H, Boden-Albala B, Elkind MS, Paik MC, Sacco RL. Carotid plaque, a subclinical precursor of vascular events: the Northern Manhattan Study. Neurology. 2008;70(14):1200-7.

62. Bittencourt MS, Hajjar LA. Insulin therapy in insulin resistance: could it be part of a lethal pathway? Atherosclerosis. 2015;240(2):400-1.

63. Barmpouletos D, Stavens G, Ahlberg AW, Katten DM, O'Sullivan DM, Heller GV. Duration and type of therapy for diabetes: impact on cardiac risk stratification with stress electrocardiographic-gated SPECT myocardial perfusion imaging. J Nuclear Cardiol. 2010;17(6):1041-9.

64. Stone NJ, Robinson JG, Lichtenstein AH, Bairey Merz CN, Blum CB, Eckel RH, Goldberg AC, Gordon D, Levy D, Lloyd-Jones DM, et al. 2013 ACC/ AHA guideline on the treatment of blood cholesterol to reduce atherosclerotic cardiovascular risk in adults: a report of the American College of Cardiology/American Heart Association Task Force on Practice Guidelines. J Am Coll Cardiol. 2014;63((25 Pt B)):2889-934.

65. Kashani A, Phillips CO, Foody JM, Wang Y, Mangalmurti S, Ko DT, et al. Risks associated with statin therapy: a systematic overview of randomized clinical trials. Circulation. 2006;114(25):2788-97.

66. Silva MA, Swanson AC, Gandhi PJ, Tataronis GR. Statin-related adverse events: a meta-analysis. Clin Ther. 2006;28(1):26-35.

67. Corrao G, Ibrahim B, Nicotra F, Soranna D, Merlino L, Catapano AL, et al. Statins and the risk of diabetes: evidence from a large population-based cohort study. Diabetes Care. 2014;37(8):2225-32.

68. Sattar N, Preiss D, Murray HM, Welsh P, Buckley BM, de Craen AJ, et al. Statins and risk of incident diabetes: a collaborative meta-analysis of randomised statin trials. Lancet. 2010;375(9716):735-42.

69. Kim S, Kyung C, Park JS, Lee SP, Kim HK, Ahn CW, et al. Normal-weight obesity is associated with increased risk of subclinical atherosclerosis. Cardiovasc Diabetol. 2015;14:58.

70. Osawa K, Miyoshi T, Koyama Y, Sato S, Akagi N, Morimitsu Y, et al. Differential association of visceral adipose tissue with coronary plaque characteristics in patients with and without diabetes mellitus. Cardiovasc Diabetol. 2014;13:61.

71. Raggi P, Shaw LJ, Berman DS, Callister TQ. Prognostic value of coronary artery calcium screening in subjects with and without diabetes. J Am Coll Cardiol. 2004;43(9):1663-9.

72. Agarwal S, Morgan T, Herrington DM, Xu J, Cox AJ, Freedman BI, et al. Coronary calcium score and prediction of all-cause mortality in diabetes: the diabetes heart study. Diabetes Care. 2011;34(5):1219-24.

73. Agarwal S, Cox AJ, Herrington DM, Jorgensen NW, Xu J, Freedman BI, et al. Coronary calcium score predicts cardiovascular mortality in diabetes: diabetes heart study. Diabetes Care. 2013;36(4):972-7.

74. Elkeles RS, Godsland IF, Feher MD, Rubens MB, Roughton M, Nugara F, et al. Coronary calcium measurement improves prediction of cardiovascular events in asymptomatic patients with type 2 diabetes: the PREDICT study. Eur Heart J. 2008;29(18):2244-51.

75. Becker A, Leber AW, Becker C, von Ziegler F, Tittus J, Schroeder I, et al. Predictive value of coronary calcifications for future cardiac events in asymptomatic patients with diabetes mellitus: a prospective study in 716 patients over 8 years. BMC Cardiovasc Disord. 2008;8:27.

76. Kramer CK, Zinman B, Gross JL, Canani LH, Rodrigues TC, Azevedo MJ, et al. Coronary artery calcium score prediction of all cause mortality and cardiovascular events in people with type 2 diabetes: systematic review and meta-analysis. BMJ. 2013;346:f1654. 